\title{
The Cause Analysis and Countermeasure Research on Urban Water Logging in Ningbo
}

\author{
Zhoufeng Wang \\ Zhejiang Agriculture and Forestry University, Hangzhou, China \\ Email:626850821@qq.com
}

How to cite this paper: Wang, Z. F. (2018). The Cause Analysis and Countermeasure Research on Urban Water Logging in Ningbo. Current Urban Studies, 6, 340-347. https://doi.org/10.4236/cus.2018.63018

Received: July 6, 2018

Accepted: August 26, 2018

Published: August 29, 2018

Copyright $\odot 2018$ by author and Scientific Research Publishing Inc. This work is licensed under the Creative Commons Attribution International License (CC BY 4.0).

http://creativecommons.org/licenses/by/4.0/

\section{c) (i) Open Access}

\begin{abstract}
As a common concern of the public and a major problem for urban construction and management, urban water logging disasters, especially in coastal cities, which are caused by extreme weather such as typhoons and continuous heavy rains, not only affect the public security of the city, the production and living order of the residents, but also lead to a lot of economic losses. Along with the continuous occurrence of urban water logging disasters, the problems of not paying attention to the drainage project and weak awareness of flood prevention in the process of urban construction have become increasingly conspicuous. Taking Ningbo City as an example, the thesis analyzes the causes of urban water logging disasters from different perspectives, and proposes specific measures to improve the prevention and management ability of urban water logging disasters in Ningbo, so as to offer helpful reference for solving similar problems to solve urban water logging disasters.
\end{abstract}

\section{Keywords}

Urban Water Logging Disasters, Cause Analysis, Prevention and Management Research

\section{Introduction}

Urban water logging is a phenomenon in which urban heavy rains or continuous rains exceed drainage capacity, resulting in water logging disasters. Under the background of global warming, extreme weather disasters around the world have increased significantly. According to statistics, over the past 10 decades, the annual average temperature of the world has increased by $0.7^{\circ} \mathrm{C}-1^{\circ} \mathrm{C}$, and the average temperature of metropolis has increased by $2^{\circ} \mathrm{C}-3^{\circ} \mathrm{C}$ (Yamato, Takahashi, \& Mikami, 2009). Research, made by scientists from all of the countries, and has confirmed that the increase of disasters caused by climate change has become an im- 
portant challenge for the global security and development (Xie, 2013). The intensity and frequency of extreme incidents have increased during recent years, and water logging disasters have become the most important disasters related to climate change which have been a sensitive issue faced by cities all over the world (Arnold \& James, 1996; Katz \& Brown, 1992; Vincenzi, De Leo, \& Bellingeri, 2012; Easterling et al., 2009; IPCC, 2012), and it affects the urban planning and construction, as well as the management and regulation of urban ecological environment.

The heavy rains brought by extreme weather have caused urban water logging disasters around the whole China. And reports on urban water logging disasters from media are common. According to a survey conducted by the Ministry of Housing and Urban Development in 2010, there were 213 cities in China that had experienced different degrees of water logging (Ye, 2015). Water logging disasters in contemporary cities have attracted much attention at the national level. The "Notice of the General Office of the State Council on Making a Efforts on the Construction of Urban Drainage and Water Logging Prevention Infrastructure" (State Office [2013] No. 23) put forward specific requirements for it, and the Ministry of Housing and Urban-Rural Development also issued the "Outline of the Comprehensive Planning for Urban Drainage (Rainfall) and Water Logging Prevention” (Huang, 2009).

Although a large number of water logging prevention and drainage projects have been constructed in cities, and non-engineering disaster reduction measures have also been taken, the problem of urban water logging has not been effectively solved, and it shows a tendency to increase in local regions. The frequent occurrence of water logging disasters in cities not only affects the urban public security and the social and economic development, but also affects the work and living order of urban residents. What's more, the problems in urban planning and construction came to light. Since the difference of geographical characteristics in various cities, the causes of water logging disasters are different. Taking a coastal city-Ningbo as an example, it is a key measure to improve the ability to prevent water logging disasters by analyzing the causes of water logging, the problems in the prevention and management of water logging, and then making prevention strategies according to different local conditions.

\section{The Problems of Water Logging Prevention in Ningbo}

\subsection{Unreasonable Layout of Urban Flood Discharge and Storage Facilities}

Along with the rapid development of the city, its flood discharge and storage facilities are also blindly constructed, lacking an excellent planning and layout. The proportion of public green space and flood storage facilities are generally small and unevenly distributed. In addition, the green space and surrounding roads of most communities are rarely designed to meet the needs of flood prevention and drainage. The position of green space is higher than roads, resulting in poor drainage and water storage. When the flood comes, it can't be dis- 
charged in time, which will make water logging. All of these are caused by not enough considerations in planning and design. At the same time, the backward idea of urban planning and construction is reflected in the transformation of a large number of permeable surfaces into roads and buildings-based impermeable underlays. But the urban rainwater system should follow the design idea of rapid discharge into rivers, making the speed increased and the runoff greatly increased in the same intensity of rainfall.

\subsection{Substandard Drainage System}

The "Code for Design of Urban Flood Control Projects", implemented on December 1, 2012 stipulates that: "if the protection of urban population $\geq 3$ million, urban drainage standard $\geq 20$ years; if the protection of urban population is 2 to 3 million people, urban drainage standard should be 10 - 20 years". In addition, the "Code for Design of Urban Outdoor Drainage", implemented in China, also requires: "The design of drainage pipe network must meet the standard of 3 - 5 years". However, the design standard for underground drainage system in Ningbo is the same as those in Shanghai, Guangzhou, Hangzhou, Wuhan, and so on, which are planned to be built according to the "occurrence for every year" standard, far lower than the standard of 10 - 20 years, even lower than "occurrence for every 3 - 5 years" urban outdoor drainage design specification. This standard can only withstand rain of $27-33 \mathrm{~mm} / \mathrm{h}$ or $100 \mathrm{~mm} / 24$ hours. Faced by sudden heavy rains, such as the typhoon "Fete" in 2013, the rainfall in Haishu District of Ningbo was at a peak, with rainfall of over $100 \mathrm{~mm}$ in one hour, total rainfall of $230 \mathrm{~mm}$, and short-term rainfall ranked top 3 in the province. Such a huge amount of rainfall exceeds the design standard for drainage pipelines, so it is too late to discharge, easily making water logging in the city.

\subsection{Imperfect Urban Flood Discharge and Storage System}

The weak urban drainage system is a direct cause of the occurrence of urban water logging. At present, many urban drainage pipelines are not systematic, of which the layout of some pipelines are unreasonable, the rainwater pipeline diameter is generally small, and the water-passing capacity is insufficient. This phenomenon is no exception in Ningbo. In China, there are almost no drain pipelines with a diameter of more than 3 meters. In some countries, cars and ships can run in drain pipelines, such as the sewers in Paris, France, with a drain pipe of about 3 meters width in the middle, and 2 pipes of about 1 meter width on both sides for maintenance. On the other hand, the management of the drainage pipeline network is not good, with a huge influence of human damaged behavior. According to the survey, the staff of the municipal drainage company attended the work for 10 times, it is about 8 times because the water outlet of water well was blocked. In addition, it is also related to the unmannerly construction in a large number of urban construction sites. For example, the reason for the accumulation of water near a construction site on Jiangnan Highway is the fact that the pipeline is dis- 
charged into a large amount of cement, sand, and so on, and a large amount of concrete is frozen in that pipeline. In other words, Ningbo has a considerable number of drainage pipes suffering from "intestinal obstruction".

\section{Cause Analysis of Water Logging in Ningbo}

The frequent occurrence of extreme weather is the objective reason which affects the urban water logging in Ningbo. And its special geographical location and climatic condition make the concentrated rainfall in a short period of time. But the fundamental causes are a series of problems, such as little attention to drainage projects, weak awareness of water logging prevention, lack of active prevention measures, and out-dated planning and construction ideas.

\subsection{Geographical Location and Climatic Condition}

On the southeast coast, Ningbo is located at the middle of the mainland coastline, the southern side of the Yangtze River Delta, the eastern end of the Ningshao Flatlands in Zhejiang, with the Zhoushan Islands as a natural barrier in the east, to the Hangzhou Bay in the north, and to Jixian, Xinchang and Shangyu in Shaoxing in the west, to Sanmen Bay in the south. And it is connected to Sanmen and Tiantai of Taizhou. Rainfall is a direct climate factor that causes urban water logging. Ningbo is a typical subtropical monsoon climate zone, along with abundant rainfall. During several years, its average annual rainfall is about 1500 $\mathrm{mm}$, of which the rainfall from April to September accounts for $70 \%$ of the year. According to statistics, since 2012, the annual rainfall has been more than the common year, especially in 2012, 2015 and 2016, respectively; it hit fresh highs of the top three in history, as shown in Table 1. What's more, there are many short and turbulent rivers in Ningbo with intensive river network. The domestic water system is composed of the Yongjiang River Basin, the Xiangshan Port and the Sanmen Bay, of which, the Yongjiang River Basin covers an area of 4518 square kilometers, holding the most developed economy and large population and the city's coastline is more than 1500 kilometers. Because the coast and river mouth are in the strong tide area of the East China Sea, influenced by the meteorology and geography influences, storm surges, droughts and floods attack fiercely, and natural disasters occur frequently. There are abundant rainfalls in Ningbo. However, when flood seasons come up or typhoons pass, the maximum rainfall around the year is around the corner. When the astronomical tide is encountered, seawater will flow backward, so there are always in trouble of water logging every year in Ningbo.

\subsection{Urbanization}

During recent years, along with the rapid development of urbanization in Ningbo, and intensive human activities, rivers and plant covers have been seriously damaged, and sediments have been deposited in rivers, leading to the reduction of flood carrying capacity. So when heavy rainfall occurs, water logging disasters 
Table 1. Rainfall in 2012-2017 (data sources: Annual report of water situation of Ningbo hydrology station in 2107) unit: $\mathrm{mm}$.

\begin{tabular}{ccccccccc}
\hline Year & 2012 & 2013 & 2014 & 2015 & 2016 & 2017 & Average & Common \\
\hline Annual rainfall & 2104 & 1621 & 1620 & 2078 & 1903 & 1596 & 1820 & 1517 \\
Over logging & $39 \%$ & $7 \%$ & $7 \%$ & $37 \%$ & $25 \%$ & $5 \%$ & $20 \%$ & - \\
Rank & First & & & Second & Third & & & \\
\hline
\end{tabular}

will happen. Taking Jiangdong District of Ningbo as an example, a large number of rivers were filled and occupied. The rate of the river network has been reduced from $8 \%$ in the early 1950 s to $4.6 \%$ at present, and there is still a large gap between the planning river network rates of about $6 \%$. What's worse, the river network has many bottlenecks, resulting in not smooth river network. At the same time, occupying rivers and canals, constructing the surrounding gates and curtain dam made wetlands, ponds, lakes, reservoirs, which originally had the function of natural storage and flood control, filled or destroyed, resulting in reducing the regulation and distribution ability of rainwater. In addition, some riverbanks have been in disrepair for a long time, and the water logging prevention and drainage facilities are out-dated, which are also likely to cause water logging disasters, to a certain extent. People have weak awareness of water logging disaster prevention and lack of active preventive measures. At the same time, the existing urban disaster prevention and emergency response system are relatively weak and the urban water logging warning and monitoring system is not sophisticated, making the pre-disaster warning and post-disaster reconstruction cannot be carried out well.

The rapid expansion of the city has brought about "cement" and "hard ground", resulting in a decrease in the urban permeable area and poor penetration of rainwater on ground. This is one of the reasons for the urban water logging. High-rise buildings of urban reinforced concrete, watertight roads of cement (asphalt), cement and brick paved sidewalks, permeable pits of more than one square meter and small sewer entrances with space covers are "cemented". According to statistics, more than $80 \%$ of the road surface in Ningbo is covered by impermeable materials such as concrete and asphalt. The underlying surface after "hard grounding", rainwater is hard to penetrate, and has to enter the urban drainage pipe network, which shortens the convergence time after the rain, accelerates the accumulation of rainwater to the various rivers, and result in the peak water flow for a short time, which will bring more pressure on the lowlands, and lead to the weakening of the natural drainage, finally urban water logging disaster occurs.

\section{Measures for Prevention and Control of Urban Water Logging in Ningbo}

Based on different coping perspectives, the Countermeasures for urban waterlogging prevention and control are also different. First, according to the urban 
planning concept, the urban waterlogging can be alleviated by realizing the coordination and coordination between different specialties and different planning projects. Pan (2004) believes that the urban vertical planning and urban waterlogging prevention can be treated by some measures, such as the local additional waterlogging stations, the high water and high drainage channels and the protection of the urban water surface. From the perspective of urban construction, the Urban Waterlogging Planning and design standards can be formulated to cope with urban waterlogging. Xie (2013) uses dynamic mathematical model to calculate the flow of rainwater design, providing a scientific basis for the prevention and control system of waterlogging, and strengthening public participation in the prevention and treatment of waterlogging in urban areas by the view of urban management. The initiative and the establishment of a sound supervision mechanism will help improve the ability of urban waterlogging prevention and control. Combined with the actual situation of urban waterlogging in Ningbo, the author suggests that the following measures should be taken.

\subsection{Planning and Update of Urban Flood Discharge and Storage Facilities}

The idea of a combination of "discharge and storage" is one of the important guiding ideologies for urban water logging management. Especially in some cities where urban drainage systems have been basically established and large-scale renovation is not available, the construction of urban discharge and storage system is one of the most important measures to deal with excessive rainfall. In order to improve the urban water logging prevention and drainage capacity of Ningbo, the principle of adapting to local conditions should be taken into account, at the same time, the characteristics of rainfall, runoff and flood, and flood discharge and storage facilities should also be comprehensively considered, and specific problems are analyzed in different regions. In order to achieve the goals of flood prevention and discharge in the near future, as well as comprehensive management in the long run, we should adopt systematic thinking mode, reduce the transformation of existing pipe network, make full use of land and rainwater, to gradually realize the construction and renewal of rainwater drainage facilities. At the same time, it is necessary to invest heavily in the construction of rainwater storage reservoirs rainwater pumping stations.

\subsection{Integrate and Reorganize the Existing Urban Water Logging Management Resources}

It is crucial to accelerate the construction of sponge city and ecological civilization in Ningbo, to strengthen the protection of urban ecology, especially the protection of water sensitive areas such as rivers, lakes, wetlands and canals, and build a reasonable ecological system. What's more, it is also necessary to improve the diversified ecological system, improve the quality of urban public environment, build urban "green road", and integrates chronic traffic system (such 
as bicycles and walking) into the urban green space system. Finally, we can increase urban green infrastructure, set up a resource network, to achieve interdisciplinary and multi-sectoral cooperation, and jointly plan an urban water logging prevention and control system.

\subsection{Improve the Design and Standard of the Drainage System}

There are always some problems of the drainage system design. Firstly, due to the limited ability of some designers, it is difficult to comprehensively consider various problems arising in the planning. Secondly, because the designers do not have to bear responsibilities, they do not seriously consider the consequences of improper design. Therefore, on the one hand, it is necessary to reduce the difficulty for designers to complete the drainage system planning by formulating detailed standards and technical guidelines; on the other hand, it is proper to gradually establish a responsibility system in the planning industry, in order to strengthen the planner's sense of responsibility.

\subsection{Collaborative Management to Establish a Governance Supervision Mechanism}

Through news agencies and media, online newspapers and other means of communication, it is a necessary way to increase publicity, improve the public's awareness of urban water logging disasters, so as to increase public participation in the prevention and control of urban water logging, while ensuring the public participation in the standardization of urban water logging control procedures, to improve effective reference for government decision-making. In addition, we should strengthen the construction of urban flood control and disaster reduction policies and regulations; improve the safeguard mechanism, so as to establish governance and supervision mechanism for urban drainage projects. Finally, we can also scientifically plan the construction of urban flood control facilities, improve the city's water logging warning information release mechanism, strengthen urban flood emergency management, and improve the city's ability to respond to water logging disasters.

\section{Conclusion}

Currently, China is still in a period of rapid urbanization, and urban underlying surface has been changing drastically. The continuous urban disasters have reflected a series of problems in urban planning and construction. The governance of urban water logging is a special project with long-term benefits. It is also a gradual and long-term process involving various interests. The construction of various measures also runs through all aspects of rainwater discharge, since any single project construction is not enough to solve the problem. So the improvement of the planning system, the overall planning of the construction, and the establishment of the system make it each other possible and are indispensable. Along with the urban construction and urbanization development, it is of prac- 
tical and strategic significance to strengthen the comprehensive governance of urban construction and to manage urban water logging as a key project of benefiting the people and the nation.

\section{Conflicts of Interest}

The author declares no conflicts of interest regarding the publication of this paper.

\section{References}

Arnold Jr., C. L., \& James, C. (1996). Impervious Surface Coverage: The Emergence of a Key Environmental Indicator. Journal of the American Planning Association, 62, 243-258. https://doi.org/10.1080/01944369608975688

Easterling, D. R., Meehl, G. A., Parmesan, C. et al. (2009). Climate Extremes: Observations, Modeling, and Impacts. Science, 289, 2068-2074. https://doi.org/10.1126/science.289.5487.2068

Huang, C. B. (2009). Discussion on Standards for Urban Flood Control and Drainage. Water Conservancy Science and Technology, No. 4, 60-61.

Inter Governmental Panel on Climate Change (IPCC) (2012). Managing the Risks of EXtreme Event Sand Disasters to Advance Climate Change Adaptation (SREX). Cambridge and New York, Cambridge University Press, 582.

Katz, R. W., \& Brown, B. G. (1992) Extreme Events in a Changing Climate: Var Ability Is More Important than Averages. Climatic Change, 21, 289-302. https://doi.org/10.1007/BF00139728

Pan, H. W. (2004). Urban Vertical Planning and Urban Governance: Exploration and Practice of Vertical Planning in Fuzhou City Center. Urban Planning, No. 5, 83-85.

Vincenzi, S., De Leo, G. A., \& Bellingeri, M. (2012). Consequences of Extreme Event Son Population Persistence and Evolution of a Quantitative Trait. Ecological Informatics, 8, 20-28. https://doi.org/10.1016/j.ecoinf.2011.12.001

Xie, Y. X. (2013). Development of Drainage Planning in View of Frequent Urban Waterlogging Disasters. City Planning, 37, 45-50

Yamato, H., Takahashi, H., \& Mikami, T. (2009). New Urban Heat Island Monitoring System in Tokyo Metropolis. Proceeding of the 7 th International Conference on Urban Climate, Yokohama, Japan, 29 June-3 July 2009.

Ye, X. D. (2015). Analysis of the Urban Waterlogging Formation Causes and Study of the Planning Countermeasures: A Case Study of Ningbo. Modern City Research, No. 10, 19-24. 